\title{
Transapical simultaneous edge-to-edge neochord repair: A new way to manage bileaflet prolapse?
}

\author{
Gilbert H. L. Tang, MD, MSc, MBA, ${ }^{a}$ and Wilson Y. Szeto, MD $^{\mathrm{b}}$
}

\footnotetext{
From the ${ }^{\mathrm{a} D e p a r t m e n t ~ o f ~ C a r d i o v a s c u l a r ~ S u r g e r y, ~ M o u n t ~ S i n a i ~ H e a l t h ~ S y s t e m, ~ N e w ~ Y o r k, ~ N Y ; ~ a n d ~ t h e ~}{ }^{\mathrm{b}}$ Division of Cardiovascular Surgery, University of Pennsylvania, Philadelphia, Pa.

Disclosures: G.H.T. is a consultant for NeoChord Inc. W.Y.S. has nothing to disclose with regard to commercial support.

Received for publication Feb 8, 2018; accepted for publication Feb 11, 2018; available ahead of print March 7 , 2018.

Address for reprints: Wilson Y. Szeto, MD, University of Pennsylvania School of Medicine, Penn Presbyterian Medical Center, Heart \& Vascular Pavilion, 2nd Floor, Suite 2A, 51 N 39th St, Philadelphia PA 19104 (E-mail: wilson.szeto@uphs.upenn.edu).

J Thorac Cardiovasc Surg 2018;156:149-50

$0022-5223 / \$ 36.00$

Copyright (C) 2018 by The American Association for Thoracic Surgery

https://doi.org/10.1016/j.jtcvs.2018.02.016
}

An attractive feature of transcatheter mitral repair technologies, is the ability to adjust the repair and reduce mitral regurgitation (MR) in real time under transesophageal echocardiographic guidance. MitraClip (Abbott Structural Heart, Santa Clara, Calif), the only FDA approved transcatheter technology that can be used to perform edge-toedge repair for primary MR, can be limited by its ability to tackle such challenging pathologies as significant prolapse or flail segments, leaving significant residual MR. ${ }^{1}$ Transapical neochordal replacement is another novel, offpump mitral repair for primary MR that has had promising early results. ${ }^{2}$ Longer term outcomes in more complex pathologies, such as anterior or bileaflet prolapse, may be less durable, as shown in the European NeoChord registry.

The challenge of repairing bileaflet prolapse is to identify a reference chord or leaflet segment to adjust the chordal length to correct the prolapse. In transapical mitral repair with the NeoChord device (NeoChord Inc, St Louis Park, Minn), as described by Colli and colleagues ${ }^{4}$ in this issue of the Journal, optimal chordal tensioning is the key to success in this procedure. This requires meticulous fine adjustment of individual chords under transesophageal echocardiographic guidance to eliminate the prolapsing segments while bringing the leaflet down into the left ventricle to maximize leaflet coaptation. In bileaflet prolapse, simultaneous individual tensioning of the neochords attached to both anterior and posterior leaflets can be difficult because of the large number of chords involved. By adding an edge-to-edge technique to the NeoChord device repair, all the chords can now be simultaneously adjusted as a single unit to fix the bileaflet prolapse and optimize leaflet coaptation, with all the deployed neochords converging to one focal point at the apex.

The reported technique is a creative opportunity to address the individual limitations of the transcatheter repair efficacy.

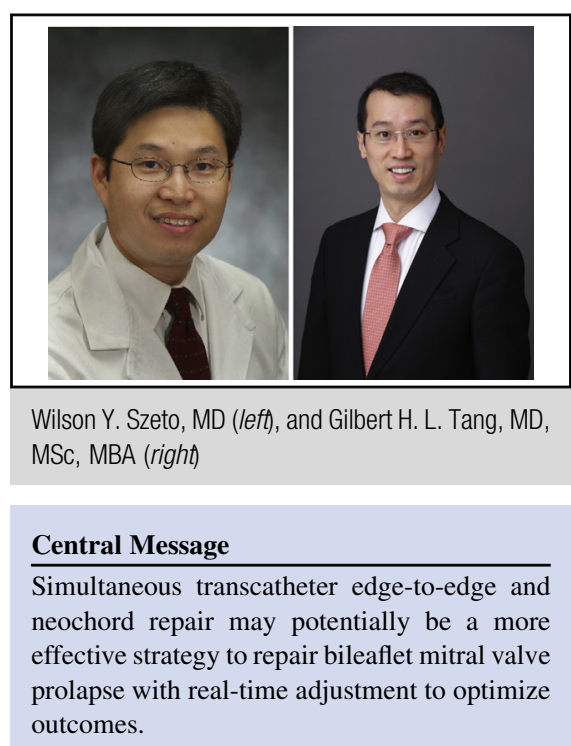

See Article page 144

edge-to-edge and chordal replacement techniques by using the 2 platforms as adjunctive therapies. In MitraClip repair, the technology relies on leaflet coaptation to reduce the MR but lacks chordal support. In NeoChord device repair, the technology relies on sufficient leaflet length and overtensioning of the neochords to maximize leaflet coaptation. Combining both techniques together during NeoChord device repair may improve the outcomes of either standalone procedure in challenging pathologies such as Barlow disease. As we have learned in surgical mitral repair, surgeons use multiple techniques to reconstruct the mitral valve. A multimodality transcatheter approach may therefore reproduce proven surgical principles of open mitral valve repair while benefiting from real-time assessment of

Not all bileaflet pathologies may be suitable, however, because creating a double-orifice valve may risk mitral stenosis. The affected leaflet segments would also need to be symmetric (eg, A2/P2 or A3/P3 prolapse/flail) for this combined edge-to-edge NeoChord device repair to work. Nonetheless, the combined technique demonstrated by Colli and colleagues ${ }^{4}$ may improve on the reparability of more complex pathologies with the NeoChord device while offering the benefit of a less invasive but more physiologic method of repairing the mitral valve. As patient advocates, surgeons must embrace innovative technology with cautious 
enthusiasm, understanding that long-term durability and outcomes comparable to proven open surgical results must be achieved.

\section{References}

1. Colli A, Manzan E, Zucchetta F, Bizzotto E, Besola L, Bagozzi L, et al. Transapical off-pump mitral valve repair with Neochord implantation: early clinical results. Int J Cardiol. 2016;204:23-8.
2. Sorajja P, Vemulapalli S, Feldman T, Mack M, Holmes DR Jr, Stebbins A, et al. Outcomes with transcatheter mitral repair in the United States: an STS/ACC TVT registry report. J Am Coll Cardiol. 2017;70:2315-27.

3. Fattouch K. Neochord for degeneration MR: data synthesis and RCT progress. Presented at: Transcatheter Cardiovascular Therapeutics Annual Meeting; October 27-November 2, 2017; Denver, CO.

4. Colli A, Besola L, Bizzotto E, Peruzzo P, Pittarello D, Gerosa G. Edge-to-edge mitral valve repair with transapical neochord implantation. J Thorac Cardiovasc Surg. 2018;156:144-8. 